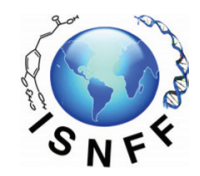

\title{
Antioxidants, polyphenols, and health benefits of cherry laurel: a review
}

\author{
Cesarettin Alasalvara ${ }^{\mathrm{a}^{*}}$ and Sui Kiat Chang ${ }^{\mathrm{b}}$
}

${ }^{a}$ TÜBITTAK Marmara Research Center, Food Institute, Gebze, Kocaeli, Turkey

${ }^{b}$ Key Laboratory of Plant Resources Conservation and Sustainable Utilization, Key Laboratory of Post-Harvest Handling of Fruits, Ministry of Agriculture, South China Botanical Garden, Chinese Academy of Sciences, Guangzhou, 510650, China

*Corresponding author: Cesarettin Alasalvar, TÜBİTAK Marmara Research Center, Food Institute, Gebze, Kocaeli, Turkey. Tel: +90 262 677 3200; E-mail: cesarettin.alasalvar@tubitak.gov.tr

DOI: $10.31665 /$ JFB.2020.10226

Received: June 1, 2020; Revised received \& accepted: June 24, 2020

Citation: Alasalvar, C., and Chang, S.K. (2020). Antioxidants, polyphenols, and health benefits of cherry laurel: a review. J. Food Bioact. 10: $47-52$.

\begin{abstract}
Cherry laurel (dark purple or black when mature) is a popular summer fruit in the Black Sea region of Turkey. It has been gaining popularity as a valuable source of healthy fruit over the last two decades and is a good source of nutrients and polyphenols together with high antioxidant activity. This contribution discusses nutritional characteristics, antioxidants, polyphenols, and health benefits of cherry laurel. Where available, comparisons are made with other cherry fruits (Cornelian, sweat, and sour) and blueberry. Although several health benefits of this fruit and its seeds have been known as home-made and traditional medicine, in vivo and well-designed human clinical trials are scarce. Therefore, additional carefully-designed human clinical trials are needed to validate the health benefits of this fruit.
\end{abstract}

Keywords: Cherry laurel; Nutrients; Antioxidants; Polyphenols; Health benefits.

\section{Introduction}

Cherry laurel (Laurocerasus officinalis Roem.) belongs to the Rosacea family and is a popular fruit (dark purple or black when mature), mainly distributed and cultivated in the coasts of the Black Sea region of Turkey and is locally called "Taflan" or "Karayemiş" (Alasalvar et al., 2005; Liyana-Pathirana et al., 2006; Alasalvar, 2016). It is native to some Asian countries, the Caucasia, Iran, some Mediterranean countries, Bulgaria, Serbia, and Western Europe (Kolayli et al., 2003; Sahan et al., 2012). Cherry laurel is mostly consumed as fresh fruit in local markets but may also be dried, pickled, and processed into syrup (known as pekmez), jam, and marmalade. Besides its use for food, both fruit and seeds of cherry laurel are well-known as traditional medicine in Turkey and have been used for many years for the treatment of stomach ulcer, digestive system complaints, bronchitis, eczemas, hemorrhoids, diuretic agent, wound healing, and hyperglycemia, among others (Baytop, 1984; Yeşilada et al., 1999; Kolayli et al.,
2003; Colak et al., 2005; Halilova and Ercisli, 2010; Turan et al., 2013; Alasalvar, 2016; Ayla et al., 2019).

This review article highlights nutritional characteristics, antioxidants, polyphenols, and health benefits of cherry laurel.

\section{Nutritional characteristics of cherry laurel}

The proximate compositions of cherry laurel are summarized in Table 1 (Kolayli et al., 2003; Alasalvar et al., 2005; Ozturk et al., 2017; Turkish Food Composition Database, 2020). Cherry laurel is a nutrient-dense fruit. Carbohydrate $(13.96-20.23 \mathrm{~g} / 100 \mathrm{~g})$ is the predominant component, followed by small amounts of protein and lipid. It contains $1.61-4.02 \mathrm{~g} / 100 \mathrm{~g}$ dietary fibre and $11.38-11.51$ $\mathrm{g} / 100 \mathrm{~g}$ sugar. Glucose is the predominant sugar, followed with fructose, in cherry laurel. With respect to minerals, cherry laurel is an excellent source of manganese $(2.27-2.42 \mathrm{mg} / 100 \mathrm{~g})$. The recommended dietary allowance (RDA) of manganese is 2.3 and 
Table 1. Nutritional characteristics of cherry laurel (per $100 \mathrm{~g}$ )

\begin{tabular}{|c|c|c|c|}
\hline Nutrient & Unit & Cherry laurel fruit ${ }^{a}$ & References \\
\hline Proximate composition & & & Alasalvar et al. (2005); Turkish Food \\
\hline Water & g & $77.28-81.21$ & Composition Database (2020) \\
\hline Energy & kcal & $74-76$ & \\
\hline Protein & g & $0.54-1.59$ & \\
\hline Lipid (fat) & g & $0.10-0.56$ & \\
\hline Ash & g & $0.43-0.79$ & \\
\hline Carbohydrate & g & $13.96-20.23$ & \\
\hline Dietary fiber & g & $1.61-4.02$ & \\
\hline Sugars & g & $11.38-11.51$ & \\
\hline Xylose & g & $0.19-0.23$ & \\
\hline Arabinose & g & $0.07-0.08$ & \\
\hline Fructose & g & $4.84-5.16$ & \\
\hline Glucose & g & $5.43-5.88$ & \\
\hline Sorbitol & g & $1.51-4.80$ & \\
\hline Sucrose & g & $\operatorname{tr}$ & \\
\hline Minerals & & & Kolayli et al. (2003); Turkish Food \\
\hline Calcium & $\mathrm{mg}$ & $14.8-53$ & Composition Database (2020) \\
\hline Copper & $\mathrm{mg}$ & $0.08-0.09$ & \\
\hline Iron & $\mathrm{mg}$ & $0.44-0.83$ & \\
\hline Magnesium & $\mathrm{mg}$ & $17.9-27.0$ & \\
\hline Manganese & $\mathrm{mg}$ & $2.27-2.42$ & \\
\hline Phosphorus & $\mathrm{mg}$ & $21-22$ & \\
\hline Potassium & $\mathrm{mg}$ & $157-222$ & \\
\hline Selenium & $\mu \mathrm{g}$ & - & \\
\hline Sodium & $\mathrm{mg}$ & $1.0-5.5$ & \\
\hline Zinc & $\mathrm{mg}$ & $0.16-0.37$ & \\
\hline Vitamins & & & Ozturk et al. (2017); Turkish Food \\
\hline Folate (DFE) & $\mu g$ & - & Composition Database (2020) \\
\hline Niacin & $\mathrm{mg}$ & $0.20-0.35$ & \\
\hline Pantothenic acid & $\mathrm{mg}$ & - & \\
\hline Pyridoxine (B-6) & $\mathrm{mg}$ & $0.06-0.07$ & \\
\hline Riboflavin & $\mathrm{mg}$ & $0.02-0.03$ & \\
\hline Thiamin & $\mathrm{mg}$ & - & \\
\hline Vitamin A (RAE) & $\mu \mathrm{g}$ & $\operatorname{tr}-3.0$ & \\
\hline Vitamin C & $\mathrm{mg}$ & $2.00-204$ & \\
\hline Vitamin E (ATE) & $\mathrm{mg}$ & - & \\
\hline Vitamin $\mathrm{K}$ & $\mu g$ & - & \\
\hline Carotenoids & & & Turkish Food Composition Database (2020) \\
\hline Beta-carotene & $\mu g$ & $\operatorname{tr}-38$ & \\
\hline Lutein & $\mu \mathrm{g}$ & $23-35$ & \\
\hline
\end{tabular}

Abbreviations: ATE, alpha-tocopherol equivalents; DFE, dietary folate equivalents; RAE, retinol activity equivalents; tr, trace. 
Table 2. Antioxidant activities of cherry laurel determined by various assays

\begin{tabular}{llll}
\hline Antioxidant assays & Unit & Cherry laurel & References \\
\hline ABTS & $\mu \mathrm{mol} \mathrm{TE} / \mathrm{g}$ & 23.21 & Celep et al. (2012); \\
BCB & \% inhibition/mL & 61 & Ozturk et al. (2017) \\
CUPRAC & $\mathrm{mg} \mathrm{AAE} / \mathrm{g}$ & $23.7-46.9$ & \\
DPPH & $\mu \mathrm{mol} \mathrm{TE} / \mathrm{g}$ & 43.54 & \\
FRAP & $\mu \mathrm{mol} \mathrm{TE} / \mathrm{g}$ & 14.74 & \\
Hydrogen peroxide scavenging & $\%$ inhibition & $3.5-16.3$ & Liyana-Pathirana et al., 2006 \\
LDL oxidation inhibition & \% inhibition & $42.7-58.5$ & \\
ORAC & $\mu$ mol TE/g & $3,633-7,996$ & Alasalvar et al., 2005 \\
Superoxide radical scavenging & \% inhibition & $82.3-100$ & Liyana-Pathirana et al., 2006 \\
\hline
\end{tabular}

Abbreviations: AAE, ascorbic acid equivalents; ABTS, 2,2'-azino-bis(3-ethylbenzothiazoline-6-sulfonic acid; BCB, beta-carotene bleaching; CUPRAC, cupric reducing antioxidant capacity; DPPH, 2,2-diphenyl-1-picrylhydrazyl; FRAP, ferric reducing antioxidant power; LDL, low-density lipoprotein; ORAC, oxygen radical absorbance capacity; TE, trolox equivalents.

$1.8 \mathrm{mg}$ per day for males and females, respectively (DRIs, 2001). It is also interesting to note that cherry laurel is rich in ascorbic acid (2.0-204 mg/100 g). Vitamin C, free radical scavenger, has a RDA of 90 and $75 \mathrm{mg}$ per day for males and females, respectively (DRIs, 2000). Considering RDA values, consuming approximately $100 \mathrm{~g}$ fresh cherry laurel supplies $100 \%$ of manganese and vitamin $\mathrm{C}$ daily.

\section{Antioxidants in cherry laurel}

Antioxidant activities of cherry laurel have been reported using various assays. These include 2,2'-azino-bis(3-ethylbenzthiazoline-6-sulphonic acid) (ABTS), beta-carotene bleaching (BCB), copper reducing antioxidant capacity (CUPRAC), 2,2-diphenyl1-picrylhydrazyl (DPPH), ferric reducing antioxidant power (FRAP), hydrogen peroxide scavenging, low-density lipoprotein (LDL) oxidation, oxygen radical absorbance capacity (ORAC), and superoxide radical inhibitory assays (Table 2).

The antioxidant activities of cherry laurel vary according to the type of antioxidant assay used (Table 2). The antioxidant capacities of cherry laurel, determined using ABTS, DPPH, FRAP, and ORAC assays, were $23.21,43.54,14.74$, and 3,633-7,996 $\mu \mathrm{mol}$ trolox equivalents (TE)/g, respectively (Alasalvar et al., 2005; Celep et al., 2012; Ozturk et al., 2017). Celep et al. (2012) reported that cherry laurel demonstrated similar antioxidant capacities with Cornelian cherry determined using BCB, CUPRAC, DPPH, FRAP, and superoxide radical inhibitory assays. In another study,
Capanoglu et al. (2011) reported that the antioxidant capacities of cherry laurel $[28.4,46.9$, and $13.3 \mathrm{mmol} \mathrm{TE} / 100 \mathrm{~g}$ dry weight (dw)] was significantly higher than sour cherry $(17.8,29.7$, and $7.6 \mathrm{mmol} \mathrm{TE} / 100 \mathrm{~g} \mathrm{dw}$ ), determined using ABTS, CUPRAC, and FRAP assays, respectively. However, the antioxidant capacities of both cherry laurel and sour cherry were significantly lower than Cornelian cherry. This happens since Cornelian cherry had the lowest degree of polymerization (DP) of proanthocyanidins (3.9) compared to both cherry laurel and sour cherry with high DP of proanthocyanidins (45.2 and 62.9, respectively) (Capanoglu et al., 2011). The DP is one of the most important properties in fruits and vegetables since antioxidant activity has been shown to depend on the DP (Hagerman et al., 1998; Jerez et al., 2007).

Table 3 presents contents of total anthocyanins, carotenoids, flavonoids, phenolics, and proanthocyanidins in cherry laurel (Alasalvar et al., 2005; Capanoglu et al., 2011; Celep et al., 2012; Ozturk et al., 2017). Cherry laurel contains much higher contents of total anthocyanins [124-174 mg cyanidin 3-glucoside equivalents (C3GE)/100 g fresh weight (fw)] and total phenolics [944-4,919 $\mathrm{mg}$ gallic acid equivalents (GAE)/100 $\mathrm{g} \mathrm{fw}$ ] than that of sweet cherry cultivars $(0.5-29.7 \mathrm{mg} \mathrm{C} 3 \mathrm{GE} / 100 \mathrm{~g}$ fw and 75-407 $\mathrm{mg}$ GAE/100 g fw, respectively (Chaovanalikit and Wrolstad, 2004). In addition, cherry laurel contains the same amount of total anthocyanins (40.62-378 $\mathrm{mg} \mathrm{C} 3 \mathrm{GE} / 100 \mathrm{~g} \mathrm{fw})$ and higher amount of total phenolics (275-695 mg GAE/100 g fw) than that of blueberry cultivars (Rodrigues et al., 2010). In terms of total carotenoids, cherry laurel has 2-fold higher total carotenoids (254-261 $\mu \mathrm{g} / 100$ g) than that of sweet cherry $(123 \mu \mathrm{g} / 100 \mathrm{~g})$ and blueberry (112

Table 3. Contents of total polyphenols in cherry laurel

\begin{tabular}{llll}
\hline Polyphenols & Unit & Cherry laurel & References \\
\hline Total anthocyanins & $\mathrm{mg} \mathrm{C3GE} / 100 \mathrm{~g}$ & $124-174$ & Alasalvar et al. (2005); Capanoglu \\
et al. (2011); Ozturk et al. (2017) \\
Total carotenoids & $\mu \mathrm{g} / 100 \mathrm{~g}$ & $254-261$ & \\
Total flavonoids & $\mathrm{mg} \mathrm{QE} / 100 \mathrm{~g}$ & 11.76 & \\
Total phenolics & $\mathrm{mg} \mathrm{FAE} / 100 \mathrm{~g}$ & $454-651$ & \\
& $\mathrm{mg} \mathrm{GAE} / 100 \mathrm{~g}$ & $944-4,919$ & Celep et al. (2012) \\
\hline
\end{tabular}

Abbreviations: C3GE, cyanidin 3-glucoside equivalents; EGCGE, epigallocatechin gallate equivalents; $F A E$, ferulic acid equivalents; GAE, gallic acid equivalents; QE, quercetin equivalents. 


\section{Table 4. Reported polyphenols in cherry laurel}

\begin{tabular}{|c|c|c|c|c|}
\hline \multicolumn{2}{|c|}{ Types of polyphenolic compounds } & \multirow{2}{*}{$\begin{array}{l}\text { Unit } \\
\mathrm{mg} / 100 \mathrm{~g} \mathrm{fw}\end{array}$} & \multirow{2}{*}{$\begin{array}{l}\text { Content } \\
4.6\end{array}$} & \multirow{2}{*}{$\begin{array}{l}\text { References } \\
\text { Capanoglu et al. (2011); Karahalil and }\end{array}$} \\
\hline Anthocyanins & Cyanidin-3-glucoside & & & \\
\hline & Cyanidin-3-rutinoside & & 6.6 & \\
\hline & Keracyanin chloride & & $2.4-14.97$ & \\
\hline & Pelargonidin-3-glucoside & & 11.0 & \\
\hline \multirow[t]{6}{*}{ Flavan-3-ols } & (-)-Catechin & & $0.02-23.3$ & \\
\hline & $(-)$-Catechin gallate & & $0.8-4.3$ & \\
\hline & (-)-Epigallocatechin & & $1.7-27.2$ & \\
\hline & (-)-Epigallocatechin gallate & & $0.4-41$ & \\
\hline & Epicatechin & & $0.3-17.2$ & \\
\hline & (-)-Gallocatechin gallate & & $1.4-6.4$ & \\
\hline \multirow[t]{3}{*}{ Flavonols } & Kaempferol & & $0.5-3.8$ & \\
\hline & Quercetin-3-glucoside & & $0.97-2.8$ & \\
\hline & Rutin & & $\mathrm{nd}-0.3$ & \\
\hline \multirow[t]{11}{*}{ Phenolic acids } & Caffeic acid & & $64.6-74.8$ & Alasalvar et al. (2005); Capanoglu et al. (2011); \\
\hline & Chlorogenic acid & & $103-160$ & $\begin{array}{l}\text { Karahalil and Şahin (2011); Karabegović et al. (2014); } \\
\text { Ozturk et al. (2017): Bayrambas et al. (2019) }\end{array}$ \\
\hline & o-Coumaric acid & & $\mathrm{nd}-2.24$ & \\
\hline & $p$-Coumaric acid & & $11.5-49.7$ & \\
\hline & Ferulic acid & & nd-6.2 & \\
\hline & Gallic acid & & $0.2-37.6$ & \\
\hline & $p$-Hydroxybenzoic acid & & $2.3-3.0$ & \\
\hline & Protocatechuic acid & & $\mathrm{nd}-1.12$ & \\
\hline & Protocatechuic acid ethyl ester & & $0.04-19.0$ & \\
\hline & Syringic acid & & $1.0-56.2$ & \\
\hline & Vanillic acid & & $1.5-12.4$ & \\
\hline Procyanidins & Procyanidin B2 & & $14.4-52.4$ & \\
\hline
\end{tabular}

Abbreviations: fw, fresh weight; nd, not detected.

$\mu \mathrm{g} / 100 \mathrm{~g}$ ) (USDA, 2019). Thus, cherry laurel may be considered as a rich source of polyphenols.

\section{Polyphenols in cherry laurel}

To the best of our knowledge, limited polyphenols (anthocyanins, flavan-3-ols, flavonols, phenolic acids, and procyanidins) have been reported in cherry laurel (Table 4). Phenolic acids (11 in total) are the main polyphenols reported in cherry laurel. Chlorogenic acid is the most abundant phenolic acid, followed by caffeic, $p$ coumaric, syringic, and gallic acids. Besides, $o$-coumaric, ferulic, $p$-hydroxybenzoic, protocatechuic, protocatechuic acid ethyl ester, and vanillic acids are also present (Alasalvar et al., 2005; Karahalil \& Şahin, 2011; Karabegović et al., 2014; Ozturk et al., 2017; Bayrambaș et al., 2019). Ayaz et al. (1997) reported the presence of protocatechuic, $p$-hydroxybenzoic, vanillic, caffeic, and $p$-coumaric acids in several cultivated and wild cherry laurel varieties where vanillic acid was the most abundant phenolic acid.

Four anthocyanins have been reported in cherry laurel (Table 4). Keracyanin chloride was the most abundant anthocyanins, as reported in a a recent study (Bayrambaş et al., 2019). Besides, cyanidin-3-glucoside, cyanidin-3-rutinoside, and pelargonidin3-glucoside were also detected in cherry laurel (Karahalil and Şahin, 2011).

Capanoglu et al. (2011) reported that the total flavan-3-ol content in cherry laurel was $1,089 \mathrm{mg} / 100 \mathrm{~g} \mathrm{dw}$ where (-)-epigallocatechin gallate and (-)-epigallocatechin were the most abundant flavan-3-ols. Besides, kaempferol was the most abundant flavonols detected in cherry laurel, followed by quercetin3 -glucoside and rutin. Cherry laurel also contains procyanidin B2 (14.4-52.5 mg/100 g fw) (Bayrambaş et al., 2019). Figure 1 shows chemical structures of the phenols and polyphenols present in cherry laurel.

\section{Health benefits of cherry laurel}

Since cherry laurel has high contents of phenolic acids, anthocyanins, and flavan-3-ols, it is able to provide health benefits beyond basic nutrition (Karahalil and Şahin, 2011; Bayrambaş et al., 2019). Cherry laurel renders beneficial effects on human health such as 


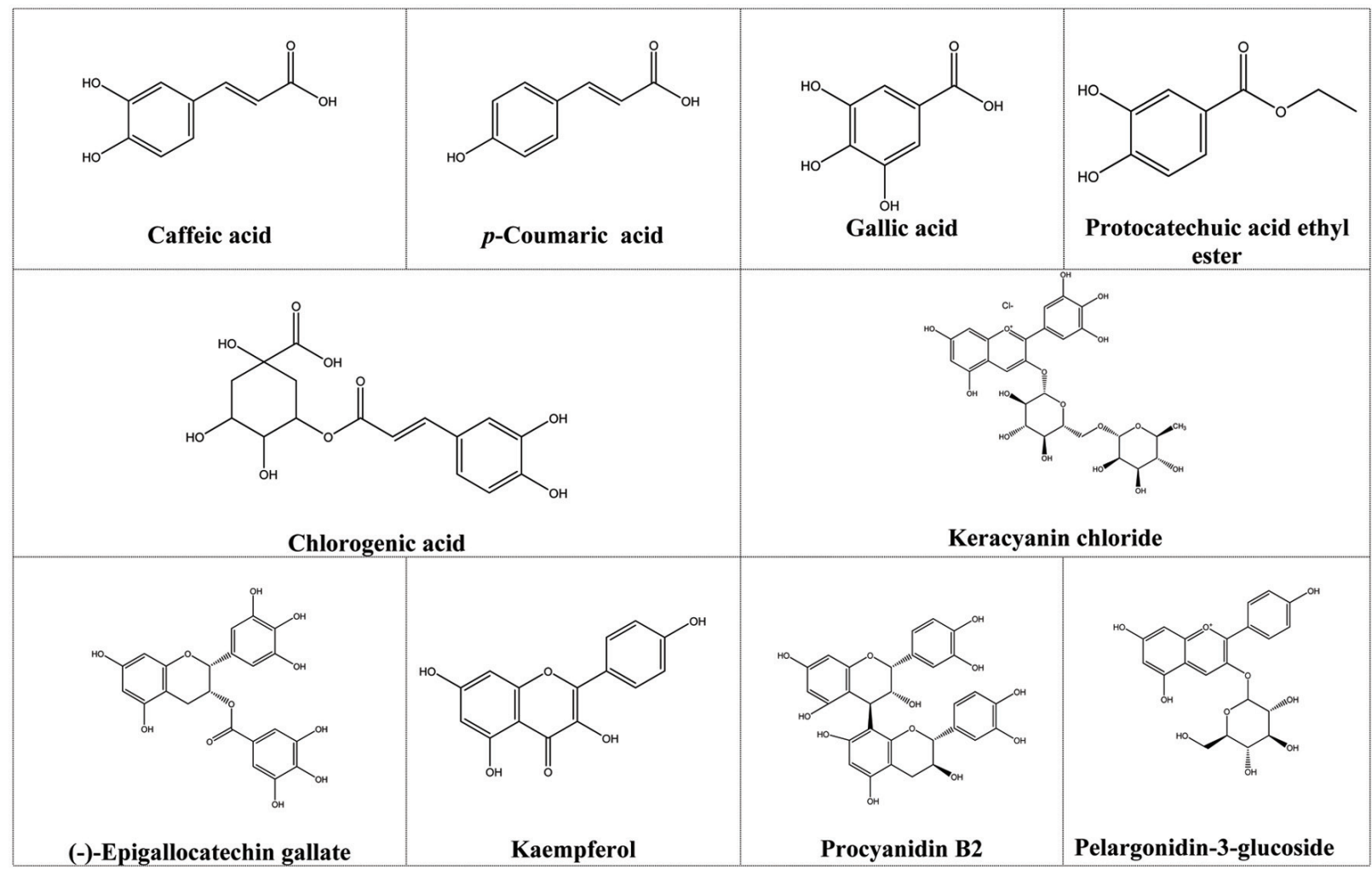

Figure 1. Chemical structures of the phenols and polyphenols present in cherry laurel.

neuroprotective, anti-diabetic, dimethoate-induced liver damage, antioxidative stress, anti-microbial, wound healing, and cytotoxic activities (Orhan and Akkol, 2011; Orhan et al., 2015; Demir et al., 2017; Eken et al., 2017; Ayla et al., 2019; Bayrambaş et al., 2019). These health effects of cherry laurel are reviewed below.

Orhan and Akkol (2011) evaluated the neuroprotective potential of cherry laurel extract. Results demonstrated that dichloromethane extract of cherry laurel (100 and $200 \mu \mathrm{g} / \mathrm{mL}$ ) showed 16.3 and $19 \%$ inhibitory activity on acetylcholinesterase, respectively, but had no effect on the activity of butyrylcholinesterase enzyme. These enzymes play important roles in the pathogenesis of Alzheimer's disease (Orhan and Akkol, 2011). More research should be conducted to ascertain the neuroprotective potential of cherry laurel.

Orhan et al. (2015) determined the effect of ethanolic extract of pitted and non-pitted cherry laurel on blood glucose levels in healthy glycemic, glucose-loaded, and streptozotocin-induced diabetic rats. Results demonstrated that pitted extract of cherry laurel (500 and $1,000 \mathrm{mg} / \mathrm{kg}$ ) showed a notable hypoglycemic effect in healthy male rats. However, pitted cherry laurel extract (1,000 and $2,000 \mathrm{mg} / \mathrm{kg}$ ) had weak inhibitory effect on blood glucose levels in glucose-loaded rats. All cherry laurel extracts had no effect on blood glucose levels in streptozotocin-induced diabetic rats (Orhan et al., 2015).

More recently, Eken et al. (2017) evaluated the protective role of methanolic extract of cherry laurel against dimethoate-induced liver damage and oxidative stress in vivo. Their results showed that pre- and post-treatment with cherry laurel extract significantly reduced the activity of alanine aminotransferase (ALT) and aspartate aminotransferase (AST) as well as total bilirubin level compared to the control group. Besides, administration of cherry laurel extract also normalized total antioxidant status by increasing the enzymatic activities of superoxide dismutase, catalase and glutathione peroxidase, reducing the malondialdehyde level, and DNA damage significantly (Eken et al., 2017). Supplementation with cherry laurel extract protected liver against hepatotoxicity by improving the structural integrity of hepatocyte cell membrane and regeneration of damaged liver cells, thus maintaining normal hepatic physiology. The liver-protective effects of cherry laurel extract were comparable to the positive control, vitamin C (Eken et al., 2017).

The antimicrobiall effects of methanolic extract of cherry laurel against five microbial strains including Gram-positive bacteria (Bacillus cereus and Staphylococcus aureus) and Gram-negative bacteria (Escherichia coli, Klebsiella pneumoniae, and Pseudomonas aeruginosa) was determined by Ayla et al. (2019), using agar diffusion method. Cherry laurel extract exhibited potential inhibitory activities against growth of the five tested human pathogenic microbes where there were no significant differences between the antimicrobial effects between Gram-positive and Gram-negative bacteria. In addition, cherry laurel extract was also investigated for wound healing effects in excisional wound mice model for ten days. Results demonstrated that topical application of cherry laurel extract on wound area accelerated wound contraction rate and enhanced epithelialization and angiogenesis in the wound healing compared to the control group (Ayla et al., 2019). The authors postulated that the antioxidant and antimicrobial effects of cherry laurel contributed to the wound healing effects.

Finally, Bayrambaş et al. (2019) investigated the cytotoxic effect of methanolic extract of three cherry laurel varieties on HCT 116 human colon cancer cell line. Treatment with $61 \mathrm{~K} 04$ variety prevented the growth of cancer cells (55\% apoptosis), followed by $61 \mathrm{~K} 05$ (27\% apoptosis), and 55K06 (36.9\% apoptosis) varie- 
ties. In another study, Demir et al. (2017) reported that dimethyl sulphoxide extract of cherry laurel exhibited potential cytotoxic effect on human colon cancer cells (WiDr) and human lung cancer cells (A549) in vitro. However, cherry laurel extract did not show any effect on the cell viability of human prostate cancer cells (PC3 ), hepatocarcinoma cells (HepG2), cervix adenocarcinoma cells (HeLa), and breast adenocarcinoma cells (MCF-7). These findings should be validated in animal models to provide better indication of the use of cherry laurel extract in preventing severity of various types of cancer.

\section{Conclusion}

The available data to date reveal that cherry laurel is rich in antioxidant phenolics and possesses strong radical scavenging activity. It is a good source of nutrients and polyphenols (mainly phenolic acids, anthocyanins, and flavan-3-ols). Limited data exist in the literature on the detailed polyphenol profiles of cherry laurel. Further research is warranted to identify other polyphenols present in cherry laurel such as anthocyanins, ellagitannins, and proanthocyanidins as well as to adressing its health benefits using welldesigned human clinical trials.

\section{References}

Alasalvar, C. (2016). Cherry laurel syrup (Pekmez). In: Shahidi, F., and Alasalvar, C. (Ed.). Handbook of functional beverages and human health. CRC Press, Taylor \& Francis Group, Boca Raton, FL, pp. 187-192.

Alasalvar, C., Al-Farsi, M., and Shahidi, F. (2005). Compositional characteristics and antioxidant components of cherry laurel varieties and pekmez. J. Food Sci. 70: S47-S52.

Ayaz, F.A., Kadioğlu, A., Reunanen, M., and Var, M. (1997). Phenolic acid and fatty acid composition in the fruits of Laurocerasus officinalis Roem. and its cultivars. J. Food Compos. Anal. 10: 350-357.

Ayla, S., Okur, M.E., Günal, M.Y., Özdemir, E.M., Çiçek Polat, D., Yoltaş, A., Biçeroğlu, Ö., and Karahüseyinoğlu, S. (2019). Wound healing effects of methanol extract of Laurocerasus officinalis Roem. Biotech. Histochem. 94: 180-188.

Bayrambaş, K., Çakır, B., and Gülseren, I. (2019). Influence of phenolic profile on the RP-HPLC detection and anti-carcinogenic potential of cherry laurel extracts from Black Sea Region-Turkey. Microchem. J. 149: 103963 .

Baytop, T. (1984). Therapy with medicinal plants in Turkey (past and present). Istanbul University Publication No. 3255, Istanbul, Turkey.

Capanoglu, E., Boyacioglu, D., de Vos, R.C., Hall, R.D., and Beekwilder, J. (2011). Procyanidins in fruit from sour cherry (Prunus cerasus) differ strongly in chain length from those in laurel cherry (Prunus lauracerasus) and Cornelian cherry (Cornus mas). J. Berry Res. 1: 137-146.

Celep, E., Aydın, A., and Yesilada, E. (2012). A comparative study on the in vitro antioxidant potentials of three edible fruits: Cornelian cherry, Japanese persimmon and cherry laurel. Food Chem. Toxicol. 50: 3329-3335.

Chaovanalikit, A., and Wrolstad, R.E. (2004). Total anthocyanins and total phenolics of fresh and processed cherries and their antioxidant properties. J. Food Sci. 69: FCT67-FCT72.

Colak, A., Özen, A., Dincer, B., Güner, S., and Ayaz, F.A. (2005). Diphenolases from two cultivars of cherry laurel (Laurocerasus officinalis Roem.) fruits at an early stage of maturation. Food Chem. 90: 801-807.

Demir, S., Turan, I., Demir, F., Demir, E.A., and Aliyazicioglu, Y. (2017). Cytotoxic effect of Laurocerasus officinalis extract on human cancer cell lines. Marmara Pharm. J. 21: 121-126.
DRIs. (2000). DRIs. Dietary reference intakes for vitamin C, vitamin E, selenium, and carotenoids. The National Academies Press, Washington, DC.

DRIs. (2001). DRIs. Dietary reference intakes for vitamin A, vitamin K, arsenic, boron, chromium, copper, iodine, iron, manganese, molybdenum, nickel, silicon, vanadium, and zinc. The National Academies Press, Washington, DC.

Eken, A., Endirlik, B.Ü., Bakir, E., Baldemir, A., Yay, A.H., and Canturk, F. (2017). Effect of Laurocerasus officinalis Roem. (cherry laurel) fruit on dimethoate induced hepatotoxicity in rats. Kafkas Üniv. Vet. Fak. Derg. 23: 779-787.

Hagerman, A.E., Riedl, K.M., Jones, G.A., Sovik, K.N., Ritchard, N.T., Hartzfeld, P.W., and Riechel, T.L. (1998). High molecular weight plant polyphenolics (tannins) as biological antioxidants. J. Agric. Food Chem. 46: 1887-1892.

Halilova, H., and Ercisli, S. (2010). Several physic-chemical characteristics of cherry laurel (Laurocerasus officinalis Roem.) fruits. Biotechnol. Biotechnol. Eq. 24: 1970-1973.

Jerez, M., Selga, A., Sineiro, J., Torres, J.L., and Nunez, M.J. (2007). A comparision between dark extracts from Pinus pinaster and Pinus radiata: Antioxidant activity and procyanidins composition. Food Chem. 100: 439-444.

Karabegović, I.T., Stojičević, S.S., Veličković, D.T., Todorović, Z.B., Nikolić, N.Č., and Lazić, M.L. (2014). The effect of different extraction techniques on the composition and antioxidant activity of cherry laurel (Prunus laurocerasus) leaf and fruit extracts. Ind. Crops Prod. 54: 142-148.

Karahalil, F.Y., and Şahin, H. (2011). Phenolic composition and antioxidant capacity of cherry laurel (Laurocerasus officinalis Roem.) sampled from Trabzon region, Turkey. Afr. J. Biotechnol. 10: 16293-16299.

Kolayli, S., Küçük, M., Duran, C., Candan, F., and Dinçer, B. (2003). Chemical and antioxidant properties of Laurocerasus officinalis Roem. (Cherry laurel) fruit grown in the Black Sea region. J. Agric. Food Chem. 51: 7489-7494.

Liyana-Pathirana, C.M., Shahidi, F., and Alasalvar, C. (2006). Antioxidant activity of cherry laurel (Laurocerasus officinalis Roem.) and its concentrated juice. Food Chem. 99: 121-128.

Orhan, I.E., and Akkol, E.K. (2011). Estimation of neuroprotective effects of Laurocerasus officinalis Roem. (cherry laurel) by in vitro methods. Food Res. Int. 44: 818-822.

Orhan, N., Damlaci, T., Baykal, T., Özek, T., and Aslan, M. (2015). Hypoglycaemic effect of seed and fruit extracts of laurel cherry in different experimental models and chemical characterization of the seed extract. Rec. Nat. Prod. 9: 379.

Ozturk, B., Celik, S.M., Karakaya, M., Karakaya, O., Islam, A., and Yarılgac, T. (2017). Storage temperature affects phenolic content, antioxidant activity and fruit quality parameters of cherry laurel (Prunus laurocerases L.). J. Food Process. Preserv. 41: e12774.

Rodrigues, E., Poerner, N., Rockenbach, I.I., Gonzaga, L.V., Mendes, C.R., and Fett, R. (2010). Phenolic compounds and antioxidant activity of blueberry cultivars grown in Brazil. Ciênc. Tecnol. Aliment., Campinas 31: 911-917.

Sahan, Y., Cansev, A., Celik, G., and Cinar, A. (2012). Determination of various chemical properties, total phenolic contents, antioxidant capacity and organic acids in Laurocerasus officinalis fruits. Acta Hortic. 939: 359-366.

Turan, M.I., Turkoglu, M., Dundar, C., Celik, N., and Suleyman, H. (2013). Investigating the effect of Prunus laurocerasus fruit extract in type II diabetes induced rats. Int. J. Pharmacol. 9: 373-378.

Turkish Food Composition Database. (2020). Turkish Food Composition Database. Cherry laurel. Published online at http://www.turkomp. gov.tr/food-cherry-laurel-570 (accessed June 20, 2020).

USDA. (2019). USDA FoodData central for SR legacy. Published online at https://fdc.nal.usda.gov (accessed June 20, 2020).

Yeşilada, E., Sezik, E., Honda, G., Takaishi, Y., Takeda, Y., and Tanaka, T. (1999). Traditional medicine in Turkey IX: folk medicine in north-west Anatolia. J. Ethnopharmacol. 64: 195-210. 